\title{
Digital Radiographic Evaluation of Primary Molar Obturation Following Use of Lentulo Spiral and Endodontic Pressure Syringe in Root Canals Prepared with Rotary Ni-Ti Files and Manual Files: An In Vivo Study
}

Priya Subramaniam ${ }^{1}$, Usha D Chandolu², Megha Gupta ${ }^{3}$

\begin{abstract}
Aim and objective: The study aimed to evaluate and compare the quality of obturation in root canals of primary molars using two methods of obturation (lentulo spiral, endodontic pressure syringe), following preparation with either rotary nickel-titanium files or manual nickel-titanium files. Materials and methods: A total of 100 primary molars from children aged 5-9 years were divided into 2 groups; consisting of 50 teeth each. In group I and group II, cleaning and shaping of root canals were done using rotary files and manual Ni-Ti files, respectively. Each group was further subdivided into 2 subgroups comprising 25 teeth each and obturated with zinc oxide eugenol, using either endodontic pressure syringe or lentulo spiral. The quality of obturation was evaluated using digital radiographs, for the length of obturation, presence, and location of voids. Data obtained were subjected to statistical analysis using Student's $t$-test, Chi-square test, and one-way ANOVA.

Results: Rotary preparation of canals with obturation using an endodontic pressure syringe resulted in fewer voids. With manual files, overfilling of canals was comparable with both techniques of obturation. More number of voids were seen in canals obturated using the lentulo spiral technique.

Conclusion: Rotary preparation of root canals followed by endodontic pressure syringe obturation gave more dense, uniform, and optimal filling than canals obturated with lentulo spiral files.

Keywords: Endodontic pressure syringe, Lentulo spiral, Obturation, Primary molars, Primary teeth, Pulpectomy, Rotary files.

Journal of South Asian Association of Pediatric Dentistry (2021): 10.5005/jp-journals-10077-3065
\end{abstract}

\section{INTRODUCTION}

Endodontic treatment of primary teeth is demanding and arduous. The primary objective of cleaning and shaping the root canal system is to remove necrotic tissue containing bacteria, provide access for irrigants to the apical third, and make space available for medicaments and the obturation. The tortuous and irregular root canal walls of primary molars require to be carefully shaped to avoid perforation of canals. The conventional hand instrumentation technique for primary teeth is time-consuming., ${ }^{1,2}$ The root canal preparation can be done faster with the use of rotary files, and so would be suitable for use in pediatric patients as children cannot cooperate for lengthy appointments. ${ }^{3-5}$ The design and flexibility of rotatory files reduce procedural errors.

An ideal obturation technique is a complete filling of the canal without over-fill and with minimal gaps or spaces. The method of mixing an obturating material as well as the technique of obturation significantly influences the success rate of root canal treatment of primary teeth. ${ }^{6-9}$ Lentulo spiral,,${ }^{8,10,11}$ endoplugger, ${ }^{12}$ and premixed syringe ${ }^{13}$ have been utilized in the obturation of root canals of primary teeth. Previous studies assessing the quality of obturation were limited to the preparation of root canals in primary teeth using conventional hand files and ex vivo conditions. $6,12,14$

Hence, this clinical study was undertaken to evaluate and compare the quality of root canal filling in primary molars following the use of lentulo spiral and endodontic pressure syringe in canals prepared with rotary Nickel-Titanium files and manual files.

\footnotetext{
1,2 Department of Pedodontics and Preventive Dentistry, The Oxford Dental College and Hospital, Bengaluru, Karnataka, India

${ }^{3}$ Department of Pedodontics and Preventive Dentistry, Vyas Dental College and Hospital, Jodhpur, Rajasthan, India
}

Corresponding Author: Priya Subramaniam, Department of Pedodontics and Preventive Dentistry, The Oxford Dental College and Hospital, Bengaluru, Karnataka, India, Phone: +91 9844225624, e-mail: drpriyapedo@yahoo.com

How to cite this article: Subramaniam P, Chandolu UD, Gupta M. Digital Radiographic Evaluation of Primary Molar Obturation Following Use of Lentulo Spiral and Endodontic Pressure Syringe in Root Canals Prepared with Rotary Ni-Ti Files and Manual Files: An In Vivo Study. J South Asian Assoc Pediatr Dent 2021;4(1):9-15.

Source of support: Nil

Conflict of interest: None

\section{Materials and Methods}

Normal, healthy, and cooperative children for the study were recruited from patients visiting the Department of Pediatric Dentistry.

\section{Estimation of Sample Size}

The sample size was estimated based on considering the difference in group means to be $20 \%$, power of the study as $80 \%$, at $95 \%$ 
confidence interval, a ratio of sample size (group I/group II) as 1 with the significance level set as $5 \%$.

So, 100 primary molars (maxillary and mandibular) requiring pulpectomy were selected from children aged between 5 years and 9 years.

Intraoral examination was done and standardized intraoral periapical radiographs were taken for the teeth with a possible indication for root canal therapy. The parents and/or caregivers were informed about the child's dentition. The nature of the study was clearly explained. Participation in the study was voluntary and prior written consent was taken from the parent/caregivers. Ethical clearance to conduct the study was obtained from the institutional review board (222/2014-15).

\section{Inclusion Criteria ${ }^{15,16}$}

- Young cooperative children with no history of systemic illness.

- Tooth with carious pulp exposure, diagnosed as having irreversible pulpitis.

- Tooth showing radiographic signs of pulpal or interradicular pathosis ranging from slight thinning of the trabeculae to furcal radiolucency.

\section{Exclusion Criteria ${ }^{16}$}

- Children with special health care needs.

- Tooth with abscess due to dental caries.

- A non-restorable tooth.

- Tooth with pulpal floor perforation.

- Tooth with more than $1 / 3$ rd root resorption.

- Pathologic bone loss.

One hundred primary molars were randomly divided into two groups of 50 teeth each, based on the method of cleaning and shaping of root canals. The primary molars were assigned to either group through random allocation with the toss of a coin (Figs 1 to 4).

Each group was further divided into 2 subgroups consisting of 25 teeth each, according to the type of obturation technique to be used. The distribution of primary molars was as follows:

Group IA: Root canals were prepared using rotary files and obturated with endodontic pressure syringe technique.
Group IB: Root canals were prepared using rotary files and obturated with the rotary lentulo spiral technique.

Group IIA: Root canals were prepared using manual Ni-Ti files and obturated with endodontic pressure syringe technique.

Group IIB: Root canals were prepared using manual Ni-Ti files and obturated with rotary lentulo spiral technique.

Following administration of local anesthesia, isolation was done with a rubber dam. Dental caries and overhanging enamel were removed with a \#330 high-speed bur under a water spray. Access to the coronal pulp was obtained using a \#8 round bur and the entire roof of the pulp chamber was removed. Necrotic tissue from the pulp chamber was removed using a sterile and sharp spoon excavator. After obtaining straight-line access, pulp tissue was extirpated from the root canals using $\mathrm{H}$ files. Working length was kept $1 \mathrm{~mm}$ short of the radiographic apex. The canals were prepared with copious irrigation using a standard volume of $5 \mathrm{~mL}$ of normal saline. In groups IA and IB, instrumentation was done with a rotary $\mathrm{NiTi}$ file together with an Endoflare, using a 1:64 Anthogyr gear reduction handpiece at a speed of about $450 \mathrm{rpm}^{2}$

The canals were first instrumented up to coronal one third using the Endoflare file at 4 point torque. This was followed by enlargement of the canal up to the working length, with the help of HERO shaper files according to the recommended sequence. ${ }^{17}$ These files were used in an "in-and-out" motion with light apical pressure. $^{18}$

In groups IIA and IIB, instrumentation was carried out using hand NiTi K files (Dentsply, Switzerland). The canals were enlarged up to three sizes more than that of the initial file and cleaning and shaping of the root canals was carried out in pullback motion.

Following complete cleaning and shaping, final irrigation with saline was carried out and the canals were dried with absorbent paper points and were obturated.

In groups IA and IIA, all root canals of the primary molars were obturated with a Pulpdent root canal sealer (Pulpdent Corporation, USA) using an endodontic pressure syringe technique as per the manufacturer's instructions.

In groups IB and IIB, all root canals of the primary molars were obturated with a homogenous mixture of zinc oxide eugenol cement (Zinc Oxide BP, Eugenol BP, Associated dental products Ltd.) using a lentulo spiral technique mounted on a slow-speed handpiece while rotating in a clockwise direction, and gently
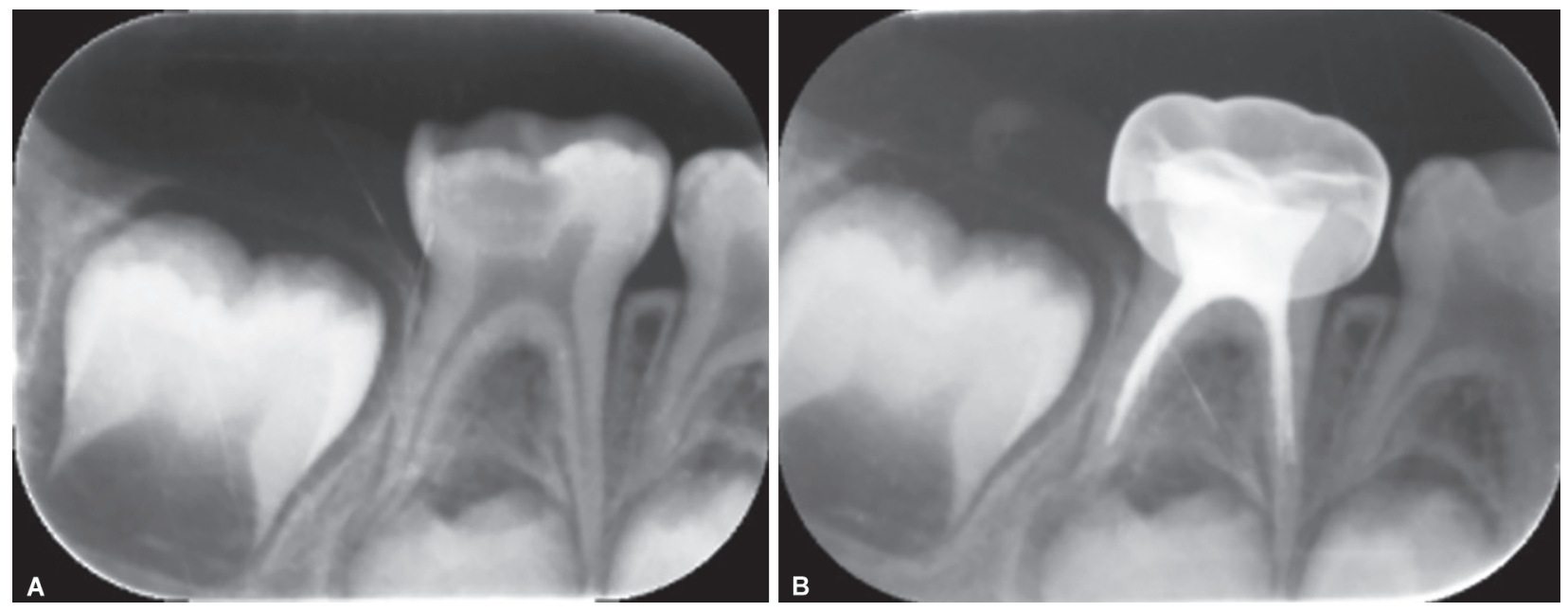

Figs 1A and B: (A) Preoperative; group I, subgroup A-Root canals prepared with rotary files and obturated with endodontic pressure syringe technique; (B) Postoperative; group I, subgroup A—Root canals prepared with rotary files and obturated with endodontic pressure syringe technique 

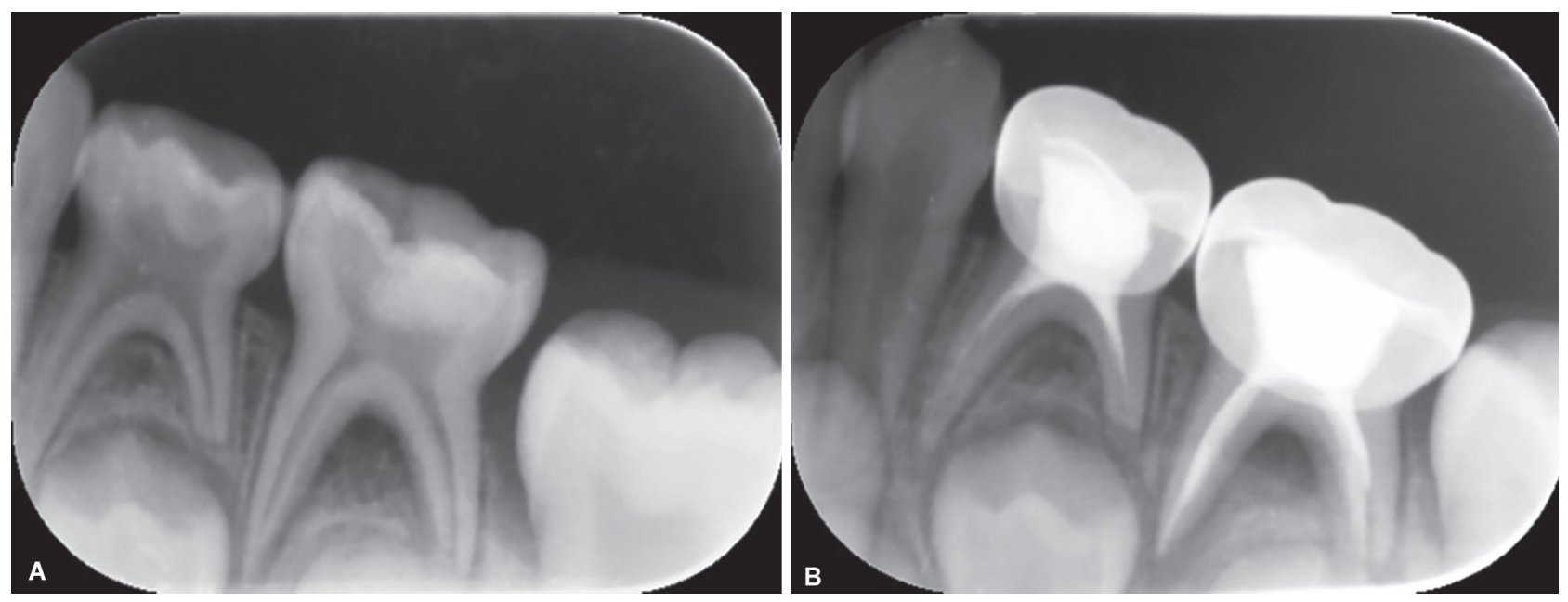

Figs $2 A$ and B: (A) Preoperative; group I, subgroup B-Root canals prepared with rotary files and obturated with rotary lentulo spiral technique; (B) Postoperative; group I, subgroup B-Root canals prepared with rotary files and obturated with rotary lentulo spiral technique
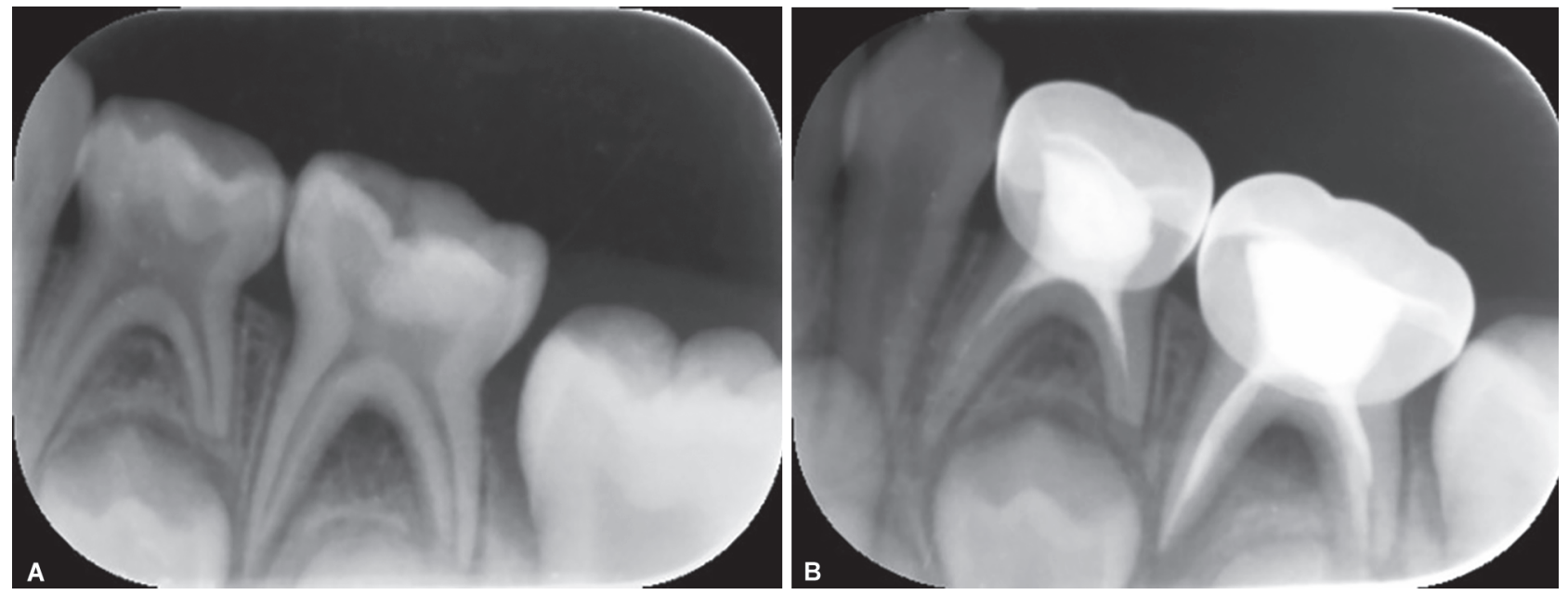

Figs 3A and B: (A) Preoperative; group II, subgroup C-Root canals prepared with manual Ni-Ti files and obturated with endodontic pressure syringe technique; (B) Postoperative; group II, subgroup C—Root canals prepared with manual Ni-Ti files and obturated with endodontic pressure syringe technique
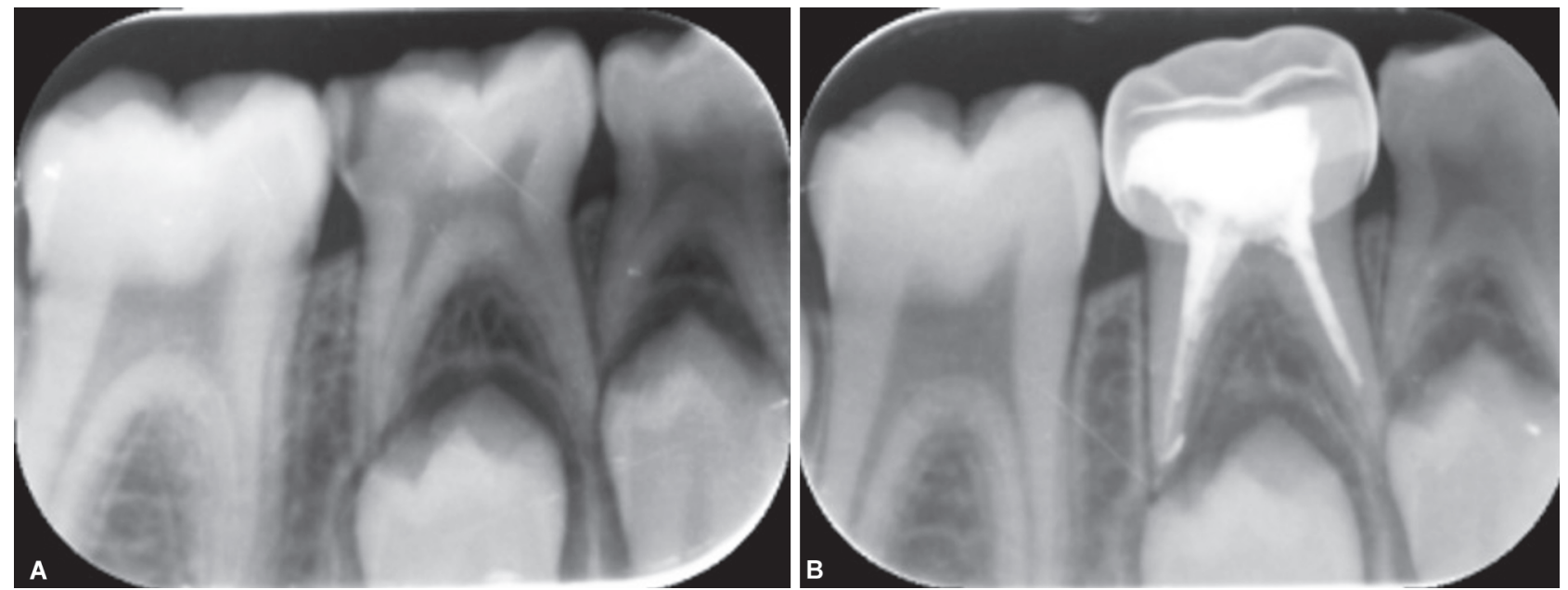

Figs 4A and B: (A) Preoperative; group II, subgroup D-Root canals prepared with manual Ni-Ti files and obturated with rotary lentulo spiral technique; (B) Postoperative; group II, subgroup D—Root canals prepared with manual Ni-Ti files and obturated with rotary lentulo spiral technique 
withdrawn from the canal while still rotating. A rubber stopper was used to keep the lentulo spiral $1 \mathrm{~mm}$ short of the working length. The process was repeated 5-7 times for each canal until the canal orifice was filled with the paste. ${ }^{12,19}$ The pulp chamber was filled with a thick mix of zinc oxide eugenol, and the teeth were restored with stainless steel crowns.

\section{Radiographic Evaluation}

Preoperative and postoperative digital radiographic images of all the primary molars were taken using sensors that were exposed with a dental X-ray unit operating at $60 \mathrm{kvp}, 6 \mathrm{~mA}, 0.3$ seconds, and $15 \mathrm{~mm}$. Radiographic images obtained with Digora PSP plates were scanned immediately after exposure (Digoraoptime, Helsinki, Finland) and stored. Radiographs were evaluated for quality of obturation by two examiners, one of them blinded for the study groups. If there was a disagreement a lower ranking was given. Evaluation of root canal obturation was done for the quality of filling as per the following criteria: ${ }^{19}$

$1=$ Less than or equal to half the root canal length was filled.

$2=$ More than half the root canal length was filled but the filling was not optimal.

$3=$ Optimal filling (canal filled to within $0-1.5 \mathrm{~mm}$ of the apex). $4=$ Filling material extruding from the apex (overfilling).

The presence or absence of voids, number and location of voids in each root canal (coronal, middle, apical) was also evaluated. ${ }^{19}$
The data obtained were subjected to statistical analysis using a Student's $t$-test (two-tailed, independent) was used to find the significance of study parameters on a continuous scale between the groups. ANOVA and Chi-square were used to find the significance of study parameters and correlation of study parameters on a categorical scale between two or more groups, respectively. The $p$ value ( $p \leq 0.05$ ) was considered as significant, $p<0.001$ was taken as highly significant. Data were analyzed using Statistical Package of Social Sciences (SPSS) software 19.0 using windows.

\section{Results}

In both the groups, none of the root canals showed obturation that was less than or equal to half the root canal length.

Following preparation with rotary files, all palatal canals were optimally filled using an endodontic pressure syringe, and overfilling was seen only in $10 \%$ of distal canals. The use of lentulo spiral gave optimal filling in $83.3 \%$ of DB canals; and overfilling was observed in $10.5 \%$ of distal, MB (5.6\%), and $25 \%$ of ML canals. In mandibular molars, $80-90 \%$ of root canals were optimally filled following obturation with the endodontic pressure syringe and $58-71 \%$ using the lentulo spiral. In maxillary molars, $92-100 \%$ of root canals showed optimal filling with the endodontic pressure syringe and $83-89 \%$ using lentulo spiral (Table 1).

Root canals prepared with manual files and obturated using an endodontic pressure syringe showed optimal filling in all DB

Table 1: Evaluation and comparison of quality of obturation between endodontic pressure syringe and lentulo spiral in root canals prepared by rotary files

\begin{tabular}{|c|c|c|c|c|c|c|}
\hline \multirow[b]{3}{*}{ Root canals } & \multirow[b]{3}{*}{ Scores } & \multicolumn{4}{|c|}{ Rotary preparation } & \multirow[b]{3}{*}{$p$ value } \\
\hline & & \multicolumn{2}{|c|}{ Group IA (endodontic pressure syringe) $N=64$} & \multicolumn{2}{|c|}{ Group IB (lentulo spiral) $N=68$} & \\
\hline & & Total no. of canals & $n(\%)$ & $n(\%)$ & Total no. of canals & \\
\hline \multirow[t]{4}{*}{ Mesial } & 1 & 13 & $0(0)$ & 7 & $0(0)$ & 0.48 \\
\hline & 2 & & $2(15.4)$ & & $2(28.6)$ & \\
\hline & 3 & & $11(84.6)$ & & $5(71.4)$ & \\
\hline & 4 & & $0(0)$ & & $0(0)$ & \\
\hline \multirow[t]{4}{*}{ Distal } & 1 & 20 & $0(0)$ & 19 & $0(0)$ & 0.23 \\
\hline & 2 & & $2(10.0)$ & & $6(31.6)$ & \\
\hline & 3 & & $16(80.0)$ & & $11(57.9)$ & \\
\hline & 4 & & $2(10.0)$ & & $2(10.5)$ & \\
\hline \multirow[t]{4}{*}{ Mesiobuccal } & 1 & 13 & $0(0)$ & 18 & $0(0)$ & 0.68 \\
\hline & 2 & & $1(7.7)$ & & $1(5.6)$ & \\
\hline & 3 & & $12(92.3)$ & & 16 (88.9) & \\
\hline & 4 & & $0(0)$ & & $1(5.6)$ & \\
\hline \multirow[t]{4}{*}{ Mesiolingual } & 1 & 10 & $0(0)$ & 12 & $0(0)$ & 0.23 \\
\hline & 2 & & $1(10.0)$ & & $1(8.3)$ & \\
\hline & 3 & & $9(90.0)$ & & $8(66.7)$ & \\
\hline & 4 & & $0(0)$ & & $3(25.0)$ & \\
\hline \multirow[t]{4}{*}{ Palatal } & 1 & 4 & $0(0)$ & 6 & $0(0)$ & 0.39 \\
\hline & 2 & & $0(0)$ & & $1(16.7)$ & \\
\hline & 3 & & $4(100)$ & & $5(83.3)$ & \\
\hline & 4 & & $0(0)$ & & $0(0)$ & \\
\hline \multirow[t]{4}{*}{ Distobuccal } & 1 & 4 & $0(0)$ & 6 & $0(0)$ & 0.45 \\
\hline & 2 & & $0(0)$ & & $1(16.7)$ & \\
\hline & 3 & & $4(100.0)$ & & $5(83.3)$ & \\
\hline & 4 & & $0(0)$ & & $0(0)$ & \\
\hline
\end{tabular}


and palatal canals. With lentulo spiral, all mesial and palatal were optimally filled. In mandibular molars, $70-75 \%$ of root canals were optimally filled using the endodontic pressure syringe and $77-100 \%$ using lentulo spiral technique. Whereas, in maxillary molars, 93-100\% of root canals showed optimal filling with the endodontic pressure syringe and $33-100 \%$ using lentulo spiral (Table 2).

A higher number of root canals obturated using lentulo spiral showed voids. In comparison to the endodontic pressure syringe, a significant difference was seen in ML canals prepared with rotary files and filled using lentulo spiral (33.3\%) $(p=0.04)$ (Tables 3 and 4). The use of an endodontic pressure syringe resulted in a higher distribution of voids in the middle third of the canals; whereas, voids were present in the middle and apical third of canals obturated using lentulo spiral. There was no significant difference (Tables 5 and 6).

\section{Discussion}

In this study, the HERO shaper files (Micro-Mega) were used which have high flexibility and a constant taper. These files have a noncutting tip and better access due to the short handle. They have a cross-section of triple helix design which reduces threading ${ }^{20}$ and prevents, by a screw-like action, the instrument from binding in the root canal. ${ }^{18}$ Anthogyr handpiece, (gear reduction of 1:64) was

Table 2: Evaluation and comparison of quality of obturation between endodontic pressure syringe and lentulo spiral in canals prepared by manual files

\begin{tabular}{|c|c|c|c|c|c|c|}
\hline \multirow[b]{3}{*}{ Root canals } & \multirow[b]{3}{*}{ Scores } & \multicolumn{4}{|c|}{ Manual preparation } & \multirow[b]{3}{*}{$p$ value } \\
\hline & & \multicolumn{2}{|c|}{ Group IIA (endodontic pressure syringe) $N=64$} & \multicolumn{2}{|c|}{ Group IIB (lentulo spiral) $N=66$} & \\
\hline & & Total no. of canals & $n(\%)$ & Total no. of canals & $n(\%)$ & \\
\hline \multirow[t]{4}{*}{ Mesial } & 1 & 11 & $0(0)$ & 9 & $0(0)$ & 0.09 \\
\hline & 2 & & $3(27.3)$ & & $0(0)$ & \\
\hline & 3 & & $8(72.7)$ & & $9(100)$ & \\
\hline & 4 & & $0(0)$ & & $0(0)$ & \\
\hline \multirow[t]{4}{*}{ Distal } & 1 & 23 & $0(0)$ & 22 & $0(0)$ & 0.54 \\
\hline & 2 & & $3(13.0)$ & & $1(4.5)$ & \\
\hline & 3 & & $16(69.6)$ & & $18(81.8)$ & \\
\hline & 4 & & $4(17.4)$ & & $3(13.6)$ & \\
\hline \multirow[t]{4}{*}{ Mesiobuccal } & 1 & 14 & $0(0)$ & 16 & $0(0)$ & 0.63 \\
\hline & 2 & & $1(7.1)$ & & $2(12.5)$ & \\
\hline & 3 & & $13(92.9)$ & & $14(87.5)$ & \\
\hline & 4 & & $0(0)$ & & $0(0)$ & \\
\hline \multirow[t]{4}{*}{ Mesiolingual } & 1 & 12 & $0(0)$ & 13 & $0(0)$ & 0.55 \\
\hline & 2 & & $2(16.7)$ & & $3(23.1)$ & \\
\hline & 3 & & $9(75.0)$ & & $10(76.9)$ & \\
\hline & 4 & & $1(8.3)$ & & $0(0)$ & \\
\hline \multirow[t]{4}{*}{ Palatal } & 1 & 2 & $0(0)$ & 3 & $0(0)$ & \\
\hline & 2 & & $0(0)$ & & $0(0)$ & \\
\hline & 3 & & $2(100)$ & & $3(100)$ & \\
\hline & 4 & & $0(0)$ & & $0(0)$ & \\
\hline \multirow[t]{4}{*}{ Distobuccal } & 1 & 2 & $0(0)$ & 3 & $0(0)$ & 0.17 \\
\hline & 2 & & & & & \\
\hline & 3 & & & & & \\
\hline & 4 & & & & & \\
\hline
\end{tabular}

Table 3: Comparison of groups in relation to the presence of voids in different root canals prepared by rotary files

\begin{tabular}{llll}
\hline & \multicolumn{2}{c}{ Rotary preparation } & \\
\cline { 2 - 3 } & $\begin{array}{l}\text { Group IA (endodontic } \\
\text { pressure syringe) }\end{array}$ & $\begin{array}{l}\text { Group IB } \\
\text { (lentulo spiral) }\end{array}$ & \\
\cline { 2 - 3 } Root canals & $n(\%)$ & $n(\%)$ & 0.29 \\
\hline Mesial & $3(23.1)$ & $1(14.3)$ & 0.15 \\
Distal & $0(0)$ & $2(10.5)$ & 0.15 \\
Mesiobuccal & $0(0)$ & $2(11.1)$ & $0.04^{*}$ \\
Mesiolingual & $0(0)$ & $4(33.3)$ & 0.31 \\
Palatal & $2(50)$ & $1(20)$ & 0.55 \\
Distobuccal & $0(0)$ & $1(20)$ & \\
\hline
\end{tabular}

Table 4: Comparison of groups in relation to the presence of voids in different root canals prepared by manual files

\begin{tabular}{|c|c|c|c|}
\hline \multirow[b]{3}{*}{ Root canals } & \multicolumn{2}{|c|}{ Manual preparation } & \multirow[b]{3}{*}{$p$ value } \\
\hline & $\begin{array}{c}\text { Group IIA (endodontic } \\
\text { pressure syringe) }\end{array}$ & $\begin{array}{c}\text { Group IIB } \\
\text { (lentulo spiral) }\end{array}$ & \\
\hline & $n(\%)$ & $n(\%)$ & \\
\hline Mesial & $0(0)$ & $2(22.2)$ & 0.29 \\
\hline Distal & $3(10.0)$ & $4(18.2)$ & 0.15 \\
\hline Mesiobuccal & $2(14.3)$ & $2(12.5)$ & 0.15 \\
\hline Mesiolingual & $0(0)$ & $0(0)$ & \\
\hline Palatal & $0(0)$ & $1(33.3)$ & 0.31 \\
\hline Distobuccal & $0(0)$ & $0(0)$ & \\
\hline
\end{tabular}

${ }^{*} p \leq 0.05$ is significant 
Table 5A: Distribution of voids in different areas of root canals in group IA

\begin{tabular}{llll}
\hline & \multicolumn{2}{c}{$\begin{array}{c}\text { Group IA (rotary preparation and obturation } \\
\text { with endodontic pressure syringe) }\end{array}$} \\
\cline { 2 - 4 } Root canals & \multicolumn{3}{c}{$n(\%)$} \\
\cline { 2 - 4 } Mesial $(N=3)$ & $2(15.4)$ & $1(7.7)$ & $0(0)$ \\
Distal $(N=0)$ & $0(0)$ & $0(0)$ & $0(0)$ \\
Mesiobuccal $(N=0)$ & $0(0)$ & $0(0)$ & $0(0)$ \\
Mesiolingual $(N=0)$ & $0(0)$ & $0(0)$ & $0(0)$ \\
Palatal $(N=2)$ & $0(0)$ & $2(50.0)$ & $0(0)$ \\
Distobuccal $(N=0)$ & $0(0)$ & $0(0)$ & $0(0)$ \\
\hline
\end{tabular}

Table 5B: Distribution of voids in different areas of root canals in group IB

\begin{tabular}{|c|c|c|c|}
\hline \multirow[b]{3}{*}{ Root canals } & \multicolumn{3}{|c|}{$\begin{array}{c}\text { Group IB (rotary preparation and obturation } \\
\text { with lentulo spiral) }\end{array}$} \\
\hline & \multicolumn{3}{|c|}{$n(\%)$} \\
\hline & Coronal & Middle & Apical \\
\hline Mesial $(N=1)$ & $1(14.3)$ & $0(0)$ & $0(0)$ \\
\hline Distal $(N=2)$ & $0(0)$ & $1(5.3)$ & $1(5.3)$ \\
\hline Mesiobuccal $(N=2)$ & $1(5.6)$ & $0(0)$ & $1(5.6)$ \\
\hline Mesiolingual $(N=4)$ & $0(0)$ & $1(8.3)$ & $3(25.0)$ \\
\hline Palatal $(N=1)$ & $0(0)$ & $0(0)$ & $1(20.0)$ \\
\hline Distobuccal $(N=1)$ & $0(0)$ & $1(20.0)$ & $0(0)$ \\
\hline
\end{tabular}

used in this study, which is more convenient to use in children due to its small head and simplicity. ${ }^{21}$

In the present study, a Pulpdent root canal sealer, which has a similar composition as zinc oxide eugenol cement was used for obturation using the endodontic pressure syringe. It is biocompatible, bacteriostatic, and radiopaque. ${ }^{22,23}$ Earlier studies have used conventional intraoral radiographs to assess the quality of root canal fillings. ${ }^{6,11,12}$ In this study, an indirect type of digital radiography using photostimulated phosphor-imaging (PSP) sensors were used. ${ }^{24,25}$ Children may not tolerate wired sensors, and may chew on the cable, or maybe more fearful of the appearance of a wired system. To better assess filled canals, computerized enhancements of the digitized image can be used to alter image contrast, measure the distance of root canal filling materials from the apex, and detect voids in the filling material. Individual canals can be more accurately evaluated. ${ }^{19}$

In the present study, root canals prepared by rotary files resulted in a better quality of obturation as compared to manual files, which may be due to a more conical form of canal preparation achieved with rotary files. ${ }^{3,26}$ Tables 1 and 2 show the comparison between the quality of obturation following preparation with manual and rotary files. This was based on radiographic criteria to evaluate the quality of obturation according to Memarpour et al. ${ }^{19}$ Although there was no significant difference, the teeth prepared by rotary files and obturated using an endodontic pressure syringe showed more number of optimally filled canals. A recent in vivo study concluded that the lentulo spiral and modified disposable syringe technique were equally effective in the obturation of primary molar root canals in terms of quality of root canal obturation. ${ }^{27}$

The higher viscosity and consistency of the material used with the endodontic pressure syringe makes the material flow under its
Table 6A: Distribution of voids in different areas of root canals in group IIA

\begin{tabular}{llll}
\hline & \multicolumn{3}{c}{$\begin{array}{c}\text { Group IIA (manual preparation and } \\
\text { obturation with endodontic pressure syringe) }\end{array}$} \\
\cline { 2 - 4 } Root canals & \multicolumn{3}{c}{$n$ Middle } \\
\cline { 2 - 4 } Mesial $(N=0)$ & $0(0)$ & $0(0)$ & Apical \\
Distal $(N=3)$ & $0(0)$ & $1(4.3)$ & $2(8.7)$ \\
Mesiobuccal $(N=2)$ & $0(0)$ & $2(14.3)$ & $0(0)$ \\
Mesiolingual $(N=0)$ & $0(0)$ & $0(0)$ & $0(0)$ \\
Palatal $(N=0)$ & $0(0)$ & $0(0)$ & $0(0)$ \\
Distobuccal $(N=0)$ & $0(0)$ & $0(0)$ & $0(0)$ \\
\hline
\end{tabular}

Table 6B: Distribution of voids in different areas of root canals in group IIB

\begin{tabular}{llll}
\hline & \multicolumn{3}{c}{$\begin{array}{c}\text { Group IIB (manual preparation and } \\
\text { obturation with lentulo spiral) }\end{array}$} \\
\cline { 2 - 4 } Root canals & \multicolumn{3}{c}{$n(\%)$} \\
\cline { 2 - 4 } Mesial $(N=2)$ & $0(0)$ & $1(11.1)$ & $1(44.4)$ \\
Distal $(N=4)$ & $1(4.5)$ & $2(9.0)$ & $1(4.5)$ \\
Mesiobuccal $(N=2)$ & $0(0)$ & $2(12.5)$ & $0(0)$ \\
Mesiolingual $(N=0)$ & $0(0)$ & $0(0)$ & $0(0)$ \\
Palatal $(N=1)$ & $0(0)$ & $1(1.33)$ & $0(0)$ \\
Distobuccal $(N=0)$ & $0(0)$ & $0(0)$ & $0(0)$ \\
\hline
\end{tabular}

own weight, once the needle is introduced in the canal. There could have been a tendency for the operator to have applied excessive pressure while extruding the material into the canal. Whereas with the lentulo spiral, a relatively high number of canals showed less than optimal filling. A probable reason could be that the correct root canal length was not maintained while fitting the rubber stop on the instrument. The frequency of overfilling was also higher following obturation using the lentulo spiral technique. Extrusion of filling material was seen to be more in the fine, narrow mesiolingual canals of primary mandibular molars. The orifices of these canals may have been sufficiently enlarged with rotary files, thus providing better access to the lentulo spiral instrument. The lentulo spiral allows the less viscous zinc oxide material to be carried further apically, during rotation of the instrument inside the canal. It may also be related to the reduction in operator "feel" during the filling procedure, with resultant overfilling.

Possible consequences of overfilling are foreign body reaction or deflection of the underlying permanent tooth when zinc oxide eugenol is used. ${ }^{10}$

Certain studies have recommended the use of the endodontic pressure syringe technique for straight canals and the lentulo spiral technique for curved canals. ${ }^{12,14}$ However, with the use of Endoflare together with rotary files, better access to the apical portion of the canals was achieved in our study. Khubchandani et al. assessed the quality of obturation in primary molars using two techniques-lentulo spiral and a pressure syringe (NaviTip). Lentulo spiral technique produced the best results in terms of length of obturation, while the NaviTip syringe was efficient enough in controlling voids and produced the best apical seal. ${ }^{28}$

Interestingly, preparation using manual files showed a higher number of under-filled mesial canals, when the endodontic pressure 
syringe was used. These canals may have remained narrow and the highly viscous material may not have flowed adequately. Conversely, a higher number of manually prepared canals were optimally filled using the lentulo spiral technique; wherein the low viscosity material was able to flow into the relatively narrow canals.

A uniform and dense obturation was seen when obturation was done using the endodontic pressure syringe. Also, the greater viscosity of the zinc oxide eugenol sealer makes it extrude with a thick rope-like consistency into the canal, resulting in a more homogeneous, dense filling and therefore, lesser voids.

In the present study, the distribution of voids was higher in the middle and apical thirds of root canals prepared with either technique of root canal preparation, and irrespective of the technique of obturation. ${ }^{19}$ Pre-enlarging the coronal third of the canal with the Endoflare instrument could have resulted in a lesser number of voids and better quality of obturation, especially in the coronal third of root canals. ${ }^{20,21}$ Endodontic pressure syringe technique of obturation following preparation with rotary files can be considered a good option for the root canal filling in primary teeth. Knowledge of rotary systems, as well as experience in handling the endodontic pressure syringe, is essential.

\section{Conclusion}

- Root canals of primary molars prepared by rotary files and obturated using endodontic pressure syringe technique resulted in a better quality of obturation than that obtained with lentulo spiral.

- In root canals prepared by manual files, there was no difference in the quality of obturation between endodontic pressure syringe and lentulo spiral techniques.

- More number of voids were observed in canals obturated using the lentulo spiral technique compared to that of the pressure syringe technique. In root canals prepared by rotary files, voids were found to be significantly higher in the mesiolingual canals.

\section{References}

1. Silva $A B L$, Leonardo $M R$, Filho NP, et al. Comparison of rotary and manual instrumentation techniques on cleaning capacity and instrumentation time in deciduous molars. J Dent Child 2004;71:4547.

2. Barr ES, Kleier DJ, Barr NV. Use of nickel-titanium rotary files for root canal preparation in primary teeth. Pediatr Dent 1999;21(7):453-454.

3. Moghaddam KN, Mehran M, Zadeh HF. Root canal cleaning efficacy of rotary and hand files instrumentation in primary molars. Iran Endod J 2009;4(2):53-57.

4. Bahrololoomi, Tabrizazadeh M, Salmani L. In vitro comparison of instrumentation time and cleaning capacity between rotary and manual preparation techniques in primary teeth. J Dent 2007;4(2):5962.

5. Nagaratna PJ, Shashikiran ND, Subbareddy VV. In vitro comparison of NiTi rotary instruments and stainless-steel hand instruments in root canal preparations of primary and permanent molar. J Ind Soc Pedod Prev Dent 2006(4):186-191. DOI: 10.4103/0970-4388.28075.

6. Bawazir OA, Salama FS. Clinical evaluation of root canal obturation methods in primary teeth. Pediatr Dent 2006;28:39-47.

7. Yacobi R, Kenny DJ, Judd PL, et al. Evoloving primary pulp therapy techniques. J Am Dent Assoc 1991;122(2):83-85. DOI: 10.14219/jada. archive.1991.0054.
8. Fuks $A B$. Pulp therapy for the primary and young permanent dentitions. Dent Clin North Am 2000;44:571-596.

9. Hargeaves KM, Cohen S. Cohen's pathways of the pulp. 10th ed., St. Louis, Mossouri: Mosby Elseiver; 2011. p. 823.

10. Coll JA, Sadrian R. Predicting pulpectomy success and its relationship to exfoliation and succedaneous dentition. Pediatr Dent 1996;18(1):57-63.

11. Guelman $M, M c E a c h e r n ~ M$, Turner C. Pulpectomies in primary incisors using three delivery systems: an in vitro study. J Clin Pediatr Dent 2004;28(4):323-326. DOI: 10.17796/jcpd.28.4.j634167443m061n3.

12. Dandashi MB, Nazif MM, ZulloT, et al. An in vitro comparison of three endodontic techniques for primary incisors. Pediatr Dent 1993;15:254-256.

13. Nurko C, Ranly DM, Garcia-Godoy F, et al. Resorption of a calcium hydroxide/iodoform paste (Vitapex) in root canal therapy for primary teeth: a case report. Pediatr Dent 2000;22:517-520.

14. Aylard SR, Johnson R. Assessment of filling techniques for primary teeth. Pediatr Dent 1987;9:195-198.

15. Dean JA, Avery DR, McDonald RE. McDonald and Avery's dentistry for the child and adolescent. 9th ed., St. Louis, Missouri: Mosby Elseiver; 2011. p. 354.

16. Welbury R, Duggal M, Hosey MT. Pediatric dentistry. 3rd ed., New York (US): Oxford University Press Inc; 2005. p. 170.

17. Calas P. HEROshapers: the adapted pitch concept. Endod Topics 2005;10(1):155-162. DOI: 10.1111/j.1601-1546.2005.00118.x.

18. Kaptan F, Sert S, Kayahan B, et al. Comparative evaluation of the preparation efficacies of HERO shaper and Nitiflex root canal instruments in curved canals. Oral Surg Oral Med Oral Pathol Oral RadiolEndod 2005;100(5):636-642. DOI: 10.1016/j.tripleo.2005. 01.013.

19. Memarpour M, Shahidi S, Meshki R. Comparison of different obturation techniques for primary molars by digital radiography. Pediatr Dent 2013;35:236-240.

20. Veltri M, Mollo A, Mantovani L, et al. A comparative study of Endo flare-Hero shaper and MtwoNiTi instruments in the preparation of curved root canals. Int Endod J 2005;38(9):610-616. DOI: 10.1111/j.1365-2591.2005.00989.x.

21. Subramaniam P, Tabrez TA, Babu KL. Microbiological assessment of root canals following use of rotary and manual instruments in primary molars. J Clin Pediatr Dent 2013;38(2):123-127. DOI: 10.17796/jcpd.38 .2.j84265t82u60271u.

22. Dogra S. Comparative evaluation of calcium hydroxide and zinc oxide eugenol as root canal filling materials for primary molars: a clinical and radiographic study. World J Dent 2011;2(3):231-236. DOI: 10.5005/ jp-journals-10015-1088.

23. Pramila R, Muthu MS, Deepa G, et al. Pulpectomies in primary mandibular molars: a comparison of outcomes using three root filling materials. Int Dent J 2016;49(5):413-421. DOI: 10.1111/iej. 12478.

24. McDonald R. Digital imaging for dentist. Aust Dent J 2001;46(4): 301-305. DOI: 10.1111/j.1834-7819.2001.tb00295.x.

25. Dean JA, Avery DR, McDonald RE. McDonald and Avery's dentistry for the child and adolescent. 9th ed., St. Louis, Missouri: Mosby Elseiver; 2011. p. 61.

26. Makarem A, Ravandeh N, Ebrahimi M. Radiographic assessment and chair time of rotary instruments in the pulpectomy of primary second molar teeth: a randomised controlled clinical trial. J Dent Res Clin Dent Prospect 2014;8(2):84-89.

27. Nagarathna C, Vishwanathan S, Krishnamurthy $\mathrm{NH}$, et al. Primary molar pulpectomy using two different obturation techniques: a clinical study. Contemp Clin Dent 2018;9(2):231-236. DOI: 10.4103/ ccd.ccd_826_17.

28. Khubchandani M, Baliga MS, Rawlani SS, et al. Comparative evaluation of different obturation techniques in primary molars: an in vivo study. Eur J Gen Dent 2017;6(1):42-47. DOI: 10.4103/2278-9626.198611. 